\title{
Physiological parameters of the isolated perfused mouse lung and their dependency on age
}

\author{
Samiya Al-Robaiy ${ }^{\mathrm{a}}$, Bernhard Hiebl ${ }^{\mathrm{b}}$, Andreas Simma, ${ }^{\mathrm{a}, \mathrm{b}}$, Rolf-Edgar Silber ${ }^{\mathrm{b}}$ \\ and Babett Bartling ${ }^{\text {a,* }}$ \\ ${ }^{a}$ Department of Cardio-thoracic Surgery, Heart Center of the University Hospital Halle (Saale), \\ Halle (Saale), Germany \\ ${ }^{\mathrm{b}}$ Center of Medical Basic Research, Medical Faculty, Martin-Luther-University Halle-Wittenberg, \\ Halle (Saale), Germany
}

\begin{abstract}
.
BACKGROUND: The "Isolated lung perfusion system" has been established to study lung physiological parameters of mice or other small animals, but little is known about the influence of age on the lung function in mice.

METHODS: We used a buffer-perfused lung system with negative-pressure ventilation to study the effect of age on physiological parameters in the isolated mouse lung. Our study included C57BL/6N mice when they were young ( 3 to 4 months), adult (5 to 9 months) or old (24 months).

RESULTS: The ex vivo data indicated that maximal function of the lung is achieved in the early adulthood (5 to 6 months of age). In this period, lung developed highest maximal expiratory flow rate which declined steadily with increasing age. After this age (>7 months) the dynamic lung compliance increased with significant changes in the 24-month-old mice. However, mouse age had no effect on airway resistance and pulmonary artery pressure. Moreover, we did not find an influence of age on the integrity of the endothelial-epithelial barrier.

CONCLUSION: Our findings indicate the importance of age, in particular on the respiratory mechanics in isolated mouse lungs, which should be considered in the pulmonary research using the "Isolated lung perfusion system".
\end{abstract}

Keywords: Airway resistance, lung compliance, C57BL/6N mice, maximal expiratory flow rate

\section{Abbreviations}

ANOVA analysis of variance

BAL broncho-alveolar lavage

$\mathrm{C}_{\text {dyn }} \quad$ dynamic lung compliance

$\mathrm{F}$ air flow

KHL Krebs-Henseleit

\footnotetext{
${ }^{*}$ Corresponding author: PD Dr. Babett Bartling, Department of Cardio-thoracic Surgery, University Hospital Halle (Saale), Ernst-Grube-Str. 40, D-06120 Halle (Saale), Germany. Tel.: +49 3455573314; E-mail: babett.bartling@uk-halle.de.
} 


$\begin{aligned} \text { MIF } & \text { maximal inspiratory flow } \\ \text { MEF } & \text { maximal expiratory flow } \\ \mathrm{R}_{\text {dyn }} & \text { dynamic airway resistance } \\ \text { SD } & \text { standard deviation } \\ \text { TNF- } \alpha & \text { tumor necrosis factor- } \alpha \\ \text { TRITC } & \text { tetramethyl-rhodamine-5-(and 6)-isothiocyanate } \\ \mathrm{V}_{\mathrm{T}} & \text { tidal volume }\end{aligned}$

\section{Introduction}

Mice are important tools to investigate the effect of substances, pathogens and diseases on the respiratory function in combination with genetic variations or active genetic manipulations. Moreover, there is an increasing interest in studying the basal or additive effect of normal aging processes on the respiratory function of mice [1,2]. Non-invasive and invasive methods are available, which can assess physiological parameters of the respiratory system in mice [3-5]. In this regard, the noninvasive whole body plethysmography and two invasive technologies using a pre-programmed ventilator each are currently applied [5].

The respiratory system includes upper airways, lung with lower airways (i.e. lung parenchyma) and thoracic cage with the respiratory muscles. In some experimental issues, such as the lung vascular effects of acute hypoxia [6], or the mechanical effect of lung-related genetic modifications [7], it is desirable to investigate specifically physiological parameters of the lung without simultaneous effect of the thoracic cage. In other approaches, it is also desirable to exclude the influence of other organs and/or the immune system. The "Isolated lung perfusion system" for mice and other small or larger animals which operates with either positive- or negative-pressure ventilation, is preferred to test new substances ex vivo for their action and toxicity prior to their application in vivo. Despite some limitations, such as the relatively short measurement time and replacement of blood by perfusion buffer, it allows continuous monitoring of several physiological lung parameters. Depending on the individual equipment of the perfusion system this can be lung compliance and airway resistance as main parameters of the respiratory mechanics as well as the pulmonary vascular resistance, edema formation and gas exchange.

Lung physiological parameters measured in mice are dependent on their genetic background [8-10]. Also, the age of mice might significantly influence respiratory mechanics, pulmonary circulation and other physiological parameters due to morphological changes of the lung during growth and aging. Morphological changes mainly include alterations in number, structure and size of the lower airways and alveoli, vessel density and elasticity of the extracellular matrix [11-15]. Although these age-related changes are mainly described for human and rat, they seem to be similar in mouse lung [16-20]. The altered ratio of lung weight to body weight with increasing somatic growth and eventually age-related cachexia is also to consider in experimental settings and data interpretation [16, 21].

Little is known about age-related physiological changes in the mouse lung under normal and/or hyperventilated conditions. However, this information might be useful for designing and interpreting physiological studies using isolated mouse lungs. Most laboratories working with the "Isolated lung perfusion system" apply low tidal volume conditions for up to three hours because long-term ventilations at higher tidal volume cause damage of the mouse lung tissue [22,23]. This again impairs the validity of data as well as the quality of lung tissue for post-analyses. Therefore, our present study aimed at the analysis of basic physiological parameters of the lung from growing, adult and old mice by use of the "Isolated lung perfusion system" ventilated at normal breathing conditions. In additions, we aimed at 
the identification of potential weaknesses of the "Isolated lung perfusion system" when used for mice of very different ages.

\section{Methods}

\subsection{Animals}

Mice with C57BL/6N background (Charles River, Sulzfeld, Germany) were investigated at different ages in this study (Table 1). All mice were housed in polycarbonate cages $\left(550 \mathrm{~cm}^{2}\right.$ area; Ehret, Emmendingen, Germany) at standard housing conditions $\left(21^{\circ} \mathrm{C}, 45-60 \%\right.$ humidity, $12: 12$ light:dark cycle, and they were regularly controlled for state of health. Out of the mice originally kept for lung investigations at advanced age, only $60 \%$ reached the age of 24 months. This animal study was performed in accordance with the guidelines approved by the local Animal Care Usage Committee, Halle (Saale).

\subsection{Lung function}

The "Isolated lung perfusion system" for mouse (Hugo Sachs Elektronik-Harvard Apparatus) was used to study the ex vivo respiratory function. The mice were anesthetized intraperitonally with ketamine and xylazin $\left(20 \mu \mathrm{g}\right.$ each. $\mathrm{kg}^{-1}$ body weight $)$ and placed in the artificial thoracic chamber. Then, the trachea was cannulated to provide constant positive-pressure ventilation $\left(90\right.$ breaths $\left.\cdot \mathrm{min}^{-1}\right)$ with room air. After abdominal incision and transdiaphragmic injection of sodium heparin ( 25 units) into the heart, the mouse was exsanguinated by transection of the vena cava. The subdiaphragmic part and the anterior chest plate were excised and discarded. The pulmonary artery was cannulated to provide a constant perfusion flow of the lung vascular bed. Krebs-Henseleit (KHL) buffer (Sigma-Aldrich, Steinheim, Germany) supplemented with $0.1 \%$ glucose, $0.3 \%$ HEPES and $2 \%$ bovine serum albumin (BSA) fraction V (AppliChem, Darmstadt, Germany) was used as perfusion buffer. This buffer was oxygenated with carbogen $\left(5 \% \mathrm{CO}_{2}\right.$, $\left.95 \% \mathrm{O}_{2}\right)$ to yield a $\mathrm{pH}$ of 7.4 and passed by means of a roller pump at constant flow $\left(1 \mathrm{ml} \cdot \mathrm{min}^{-1}\right)$. After starting the perfusion via the pulmonary artery, the left ventricle was immediately opened with a small incision at the apex of the heart to allow the efflux of the perfusate. The left atrium was cannulated by passing the cannula through apex and mitral valve. The respiratory mechanics and perfusate characteristics were continuously acquired by the PULMODYN ${ }^{\circledR}$ Pulmonary Mechanics Data Acquisition software (Hugo Sachs Elektronik-Harvard Apparatus). The lid of the artificial thoracic chamber was closed, and the ventilation was switched to negative pressure ventilation ( 90 breaths $\cdot \mathrm{min}^{-1}$ ) with regular induction of a deep inspiration (one augmented breath after four minutes). KHL perfusion buffer and isolated lung were maintained at $37^{\circ} \mathrm{C}$ throughout the experiment by use of a circulatory water bath. In all cases, we applied a constant end-expiratory pressure of $-2 \mathrm{~cm} \mathrm{H}_{2} \mathrm{O}$ and a variable inspiratory pressure (-8 to $-11 \mathrm{~cm} \mathrm{H}_{2} \mathrm{O}$ ) in the artificial thoracic chamber (corresponds to the minimal and maximal negative pleural pressure $\left(\mathrm{P}_{\text {pleu }}\right)$, respectively) to reach a tidal volume $\left(\mathrm{V}_{\mathrm{T}}\right)$ of $7 \mu \mathrm{l} \cdot \mathrm{g}^{-1}$ body weight. After an equilibration period of $20 \mathrm{~min}$, the lung physiological data were recorded for $90 \mathrm{~min}$. Figure 1 shows the raw data of five breathing cycles of a selected experiment for the airflow $(F), V_{T}, P_{\text {pleu }}$ and pulmonary artery pressure (PAP). Dynamic airway resistance at $70 \% \mathrm{~V}_{\mathrm{T}}\left(\mathrm{R}_{\mathrm{dyn}}\right)$ and dynamic lung compliance at zero air flow $\left(\mathrm{C}_{\mathrm{dyn}}\right)$ were calculated simultaneously according to the given equations (Fig. 1).

At the end of each experiment, lung was perfused with KHL buffer containing $1 \mathrm{mg} \cdot \mathrm{ml}^{-1}$ tetramethylrhodamine-5-(and 6)-isothiocyanate (TRITC)-labeled dextran (65-85 kDa; Sigma-Aldrich, 


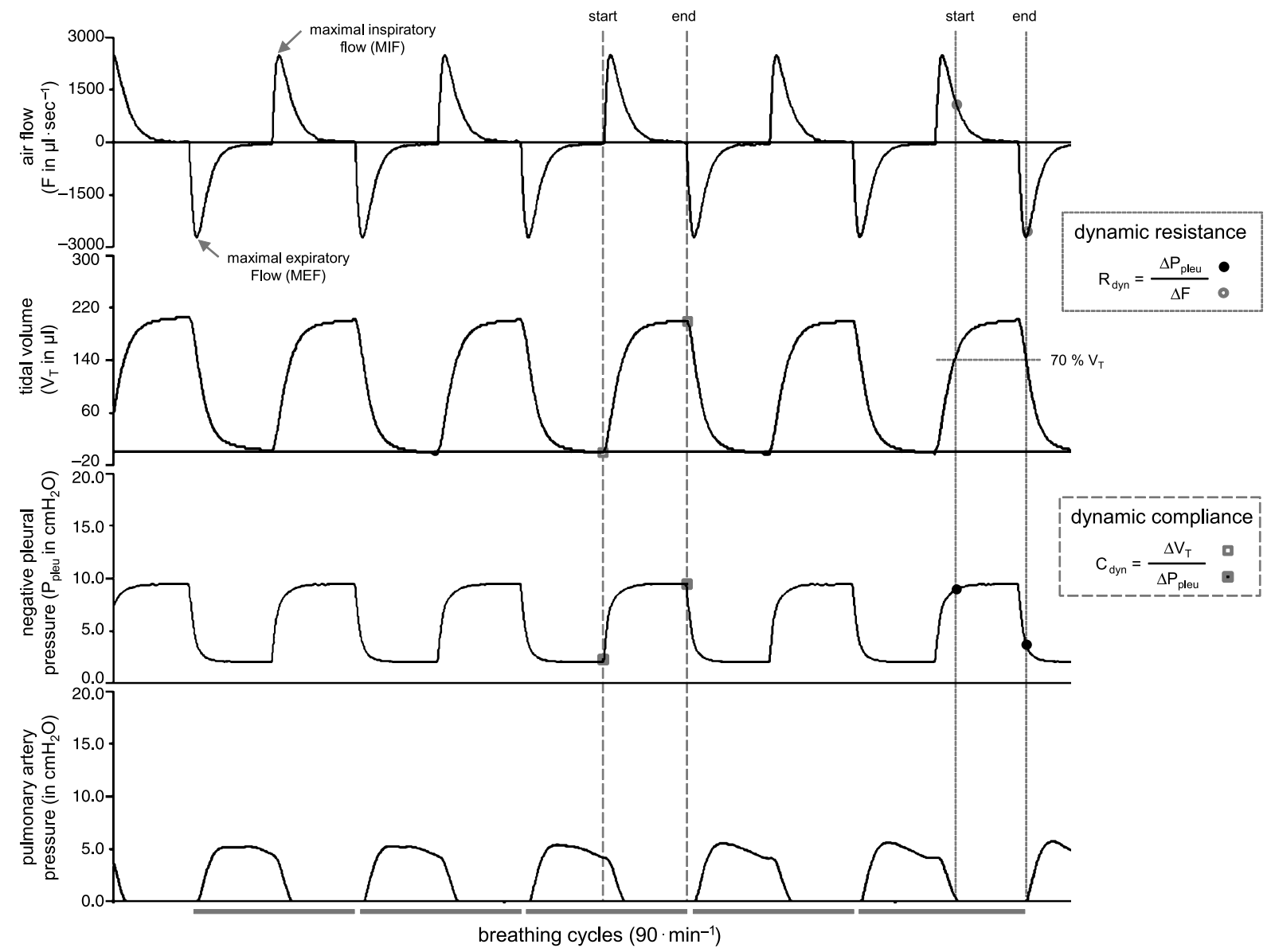

Fig. 1. Selected raw data for respiratory mechanics and perfusate pressure of the isolated mouse lung as acquired and computed by the "Isolated lung perfusion system" with Data Acquisition software. $\mathrm{R}_{\mathrm{dyn}}$ and $\mathrm{C}_{\mathrm{dyn}}$ were calculated according to the given equations [26].

Steinheim, Germany) to determine the vascular permeability. TRITC-labeled dextran-containing buffer was replaced after 7 min by standard KHL buffer and the perfusion was continued for further 3 min. Thereafter, the lung was lavaged three-times with $0.5 \mathrm{ml}$ saline via the cannulated trachea. The bronchoalveolar lavage (BAL) fluids were pooled, centrifuged for cell removal and stored at $-80^{\circ} \mathrm{C}$ for further analysis.

\subsection{BAL analysis}

Lung vascular permeability was determined by quantifying TRITC-labeled dextran in the BAL fluid per TRITC-dextran standard series $\left(550 \mathrm{~nm}\right.$ excitation, $590 \mathrm{~nm}$ emission) using the infinite ${ }^{\circledR}$ M1000 fluorescence reader (Tecan, Grödig, Austria). Total protein was determined with the BCA Protein Assay Reagent kit (Pierce, Rockford, IL) and tumor necrosis factor- $\alpha$ (TNF- $\alpha$ ) with the mouse TNF- $\alpha$ ELISA Ready-SET-Go kit (eBioscience, Frankfurt, Germany) according to manufactures' instructions. 
Table 1

Mice of study

\begin{tabular}{llcccc}
\hline Group & Age & Notal range & $\begin{array}{c}\text { Number } \\
n\end{array}$ & $\begin{array}{c}\text { Gender } \\
n\end{array}$ & $\begin{array}{c}\text { Body weight } \\
\text { Mean } \pm \text { SD }\end{array}$ \\
\hline Young & 3 months & $89-96 \mathrm{~d}$ & 10 & $4 \%, 3 \sigma^{7}$ & $23.3 \pm 3.6$ \\
& 4 months & $124-133 \mathrm{~d}$ & 5 & $5 \%,-\sigma^{7}$ & $24.3 \pm 3.8$ \\
Adult & 5 months & $141-169 \mathrm{~d}$ & 6 & $5 \%, 1 \sigma^{7}$ & $25.8 \pm 1.9^{*}$ \\
& 6 months & $179-186 \mathrm{~d}$ & 7 & $7 \%,-\sigma^{7}$ & $27.2 \pm 1.4^{*}$ \\
& 7 months & $206-215 \mathrm{~d}$ & 5 & $3 \%, 2 \sigma^{7}$ & $31.1 \pm 3.1^{*}$ \\
& 8 months & $231-245 \mathrm{~d}$ & 6 & $3 \%, 3 \sigma^{7}$ & $30.4 \pm 4.2^{*}$ \\
& 9 months & $364-376 \mathrm{~d}$ & 5 & $4 \%, 1 \sigma^{7}$ & $31.7 \pm 2.8^{*}$ \\
Old & 24 months & $700-738 \mathrm{~d}$ & 14 & $6 \%, 8 \sigma^{7}$ & $28.9 \pm 3.7^{*}$ \\
\hline
\end{tabular}

${ }^{*} P<0.01$ versus 3 -month-old as determined by ANOVA test (further significances are not indicated).

\subsection{Statistical analysis}

Data are reported as mean \pm standard deviation $(\mathrm{SD})$ or as median with range or individual data. Data presentations and statistical calculations were performed by use of the SigmaPlot 10 and SigmaStat 3.5 softwares (Systat Software Inc., San Jose, CA). The one-way analysis of variance (ANOVA) procedure followed by Student-Newman-Keuls method or, in the case of non-parametric data, the one-way ANOVA procedure on Ranks followed by Dunn's method was applied as statistical test. $P$ values $<0.05$ indicate a significant difference between the groups.

\section{Results}

Lung physiological parameters of C57BL/6N mice were studied ex vivo by use of a buffer-perfused lung system which operates with negative-pressure ventilation similar to in vivo conditions. As listed in Table 1, we studied mice when they were young ( 3 to 4 months), adult (5 to 9 months) or old ( 24 months). The terms "young", "adult" and "old" have been assigned according to both biological age and weight development of the mice (Table 1). Our age groups comprised female and male mice in different numbers (Table 1), however, in contrast to the whole respiratory system [10], no sex-dependent differences in the biomechanics of the isolated lung could be identified [7]. In order to avoid inhomogeneity in ventilation due to differences in the lung size, all lungs were ventilated constantly at a body weight-adapted $\mathrm{V}_{\mathrm{T}}$. Although it does not absolutely ensure the same air volume in the lung in relation to the total lung capacity, the $\mathrm{V}_{\mathrm{T}}$ adjustment according to the body weight is still the best method to reach similar ventilations and, therefore, it is applied by most groups [6, 22, 24, 25].

Due to age-related differences in the body weight (Table 1), the experimental $V_{T}$ was lower in young mice than in adult and old mice (Fig. 2A). Moreover, dynamic compliance $\left(\mathrm{C}_{\mathrm{dyn}}\right)$ of isolated mouse lungs was dependent on age. As shown in Fig. 2B, $\mathrm{C}_{\mathrm{dyn}}$ remained constant for mice between 3 and 6 month of age but increased at higher ages with significant changes in 24-month-old mice. In comparison to static lung compliance $\left(\mathrm{C}_{\text {stat }}\right), \mathrm{C}_{\mathrm{dyn}}$ is also a function of the resistive force $(\mathrm{R} \cdot \mathrm{F})$, which needs to be overcome. Since $C_{d y n}$ is computed when the air flow is zero (Fig. 1), the calculation of $C_{d y n}$ corresponds with the 

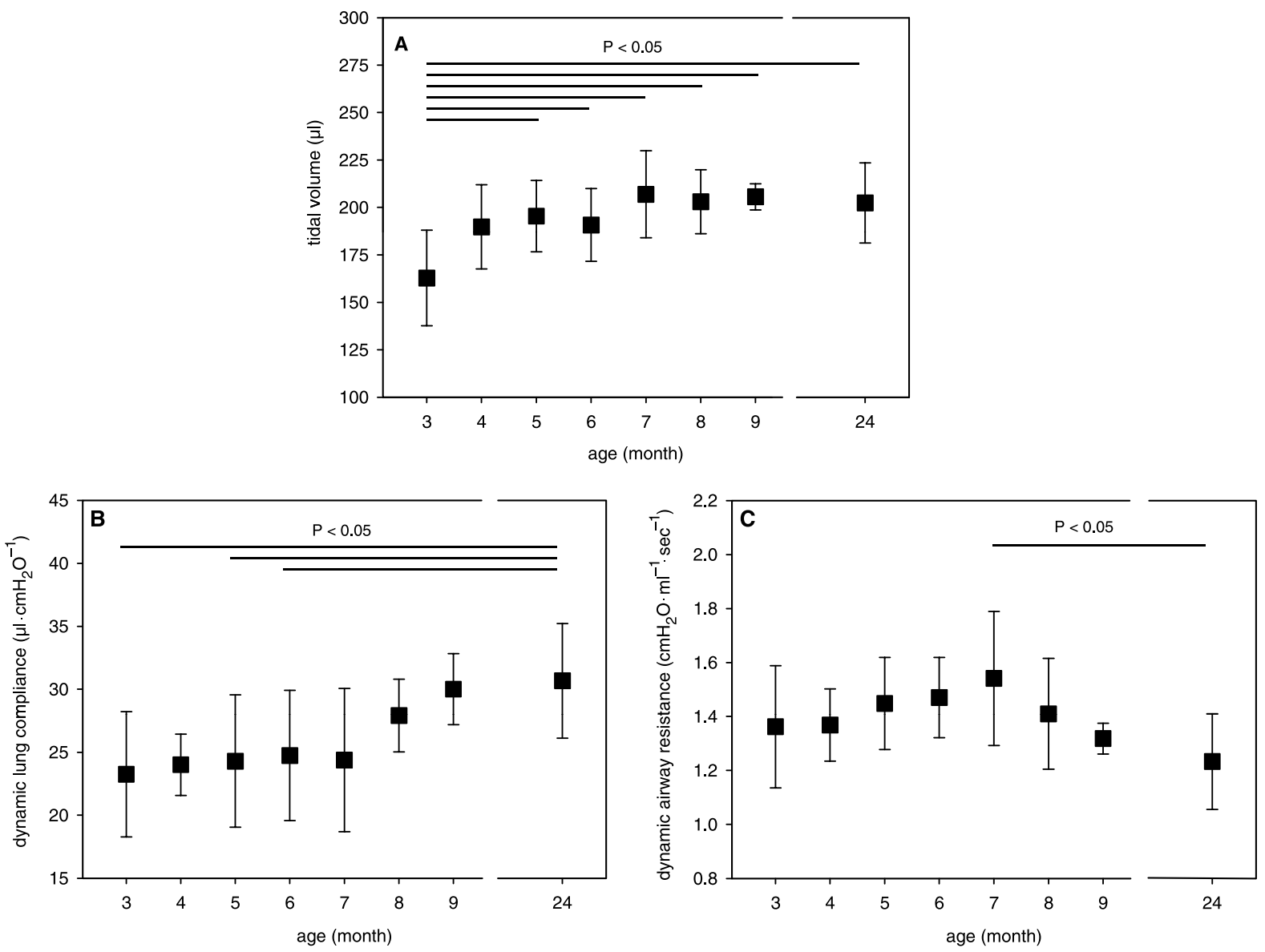

Fig. 2. Age-dependency of $A$ ) experimental $V_{T}, B$ ) $C_{d y n}$ at zero air flow and $C$ ) $R_{d y n}$ at $70 \% V_{T}$ in isolated mouse lungs. Mean data \pm SD are given with $P<0.05$ as determined by ANOVA test.

$\mathrm{C}_{\text {stat }}$ calculation [26]. Moreover, the dynamic airway resistance $\left(\mathrm{R}_{\mathrm{dyn}}\right)$ was only moderately influenced by age with slight reduction in lungs from old mice as compared to adult mice (Fig. 2C).

Peak flow analyses showed that the maximal expiratory flow (MEF) at weight-adapted $\mathrm{V}_{\mathrm{T}}$ was lower in the youngest age group than in the other age groups (Fig. 3A). Since youngest mice were also ventilated with the lowest $\mathrm{V}_{\mathrm{T}}$, our data indicate a relationship between MEF and lung volume. In growing humans, this relationship was described by the power law equation: $\mathrm{MEF}=a$ lung volume $(\mathrm{V})^{b}[27-29]$. Therefore, we analysed the relation between MEF and weight-adapted $\mathrm{V}_{\mathrm{T}}$ applied for ventilation in our isolated mouse lungs. Regression analyses calculated the exponent $b$ (slope of the regression) with 0.534 for all mice (Fig. 3B). Subsequent correction of the MEF data by the individual $\mathrm{V}_{\mathrm{T}}{ }^{0.534}$ revealed no significant differences between the age groups but still indicated highest MEF in 4- to 6-month-old mice (Fig. 3C). However, age-dependent subgroup analyses calculated different exponents for the relation between MEF and $\mathrm{V}_{\mathrm{T}}$ with highest values for the young mice (Fig. 3B). Since the airway resistance was less influenced (Fig. 2C), we then normalized the MEF per maximal inspiratory flow (MIF), which was independent of age (data not shown). This MIF-corrected MEF was highest in isolated lungs from 5-month-old mice as compared to lungs from younger mice and decreased steadily with increasing age (Fig. 3D). 

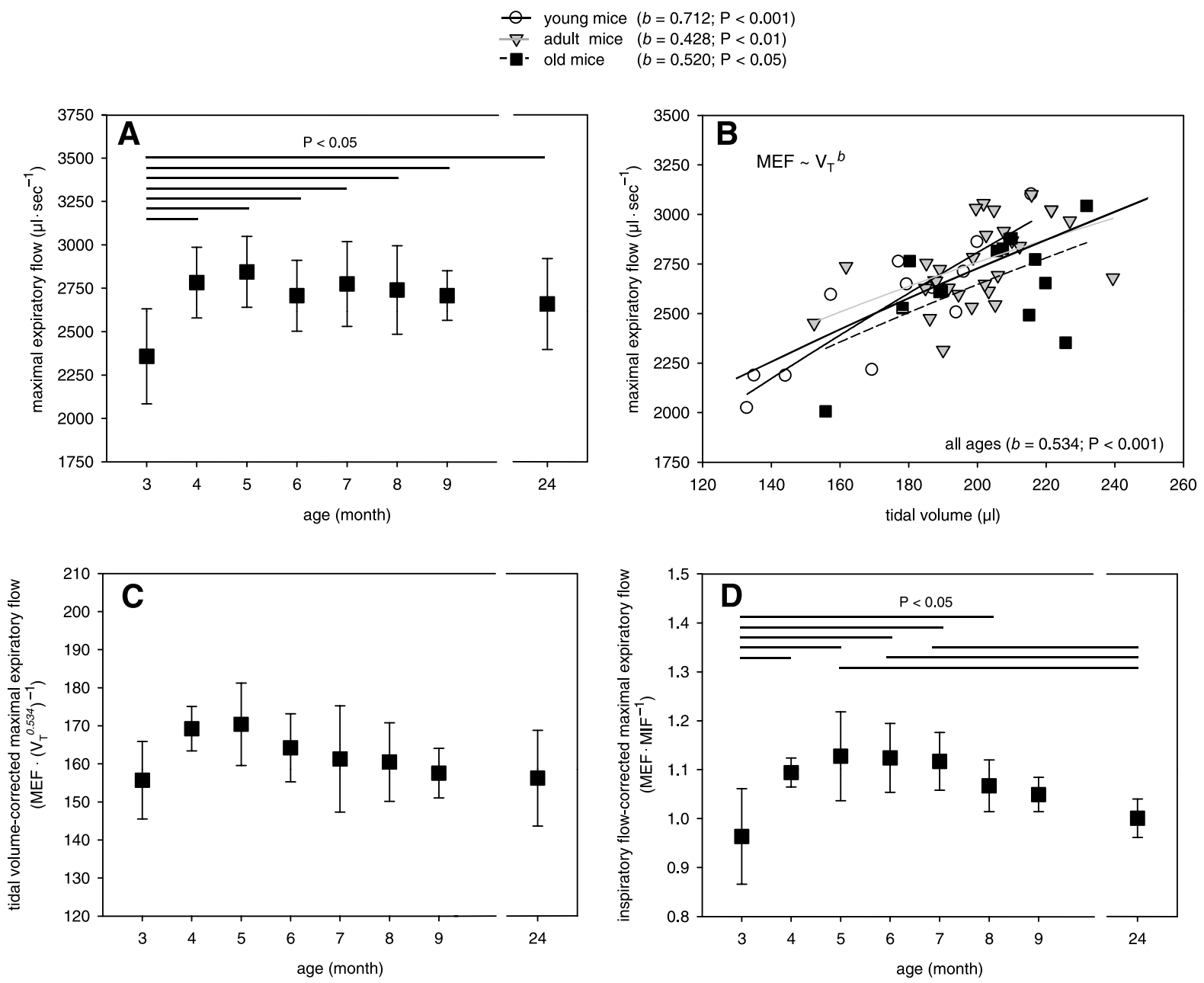

Fig. 3. Effect of growth and aging on the airflow in isolated mouse lungs. A) MEF, B) MEF in relation to $\left.V_{T}, C\right) V_{T}$-corrected MEF, and D) MIF-corrected MEF. Mean data \pm SD are given with $P<0.05$ as determined by ANOVA test.

Our buffer-perfused lung system also allowed the detection of the mean perfusion pressure in pulmonary arteries, but these measurements did not reveal a significant effect of age (Fig. 4). The integrity of the endothelial-epithelial barrier was assessed by detection of TRITC-labelled dextran in the BAL, which was added to the perfusate shortly before. The quantification of diffused TRITC-labelled dextran did not indicate an influence of age on the lung vascular permeability and, therefore, edema formation in the isolated mouse lungs (Table 2). This observation was also confirmed by an unchanged protein concentration in the BAL fluid (Table 2). Moreover, we did not find an influence of mouse age on the BAL concentration of TNF- $\alpha$ released from the lung cells before and/or during the experiment (Table 2).

\section{Discussion}

Using the "Isolated lung perfusion system" we demonstrated that growth and aging is associated with biomechanical changes of the mouse lung under normal breathing conditions. Despite some disadvantages 
Table 2

BAL after ex vivo lung perfusion

\begin{tabular}{lccc}
\hline Age group & $\begin{array}{c}\text { Permeable dextran } \\
\left(\mathrm{ng} \cdot \mathrm{ml}^{-1}\right) \text { Mean } \pm \mathrm{SD}\end{array}$ & $\begin{array}{c}\text { Protein }\left(\mu \mathrm{g} \cdot \mathrm{ml}^{-1}\right) \\
\text { Mean } \pm \mathrm{SD}\end{array}$ & $\begin{array}{c}\mathrm{TNF}-\alpha\left(\mathrm{pg} \cdot \mathrm{ml}^{-1}\right) \\
\text { Mean } \pm \mathrm{SD}\end{array}$ \\
\hline 3 month & $707 \pm 396$ & $357 \pm 104$ & $51 \pm 13$ \\
4 month & $639 \pm 382$ & $382 \pm 139$ & $98 \pm 69$ \\
5 month & $620 \pm 181$ & $296 \pm 107$ & $96 \pm 45$ \\
6 month & $1096 \pm 628$ & $358 \pm 181$ & $81 \pm 53$ \\
7 month & $1067 \pm 803$ & $390 \pm 165$ & $78 \pm 15$ \\
8 month & $657 \pm 143$ & $556 \pm 155$ & $61 \pm 17$ \\
9 month & $643 \pm 132$ & $275 \pm 99$ & $88 \pm 23$ \\
24 month & $648 \pm 318$ & $488 \pm 115$ & \\
\hline
\end{tabular}

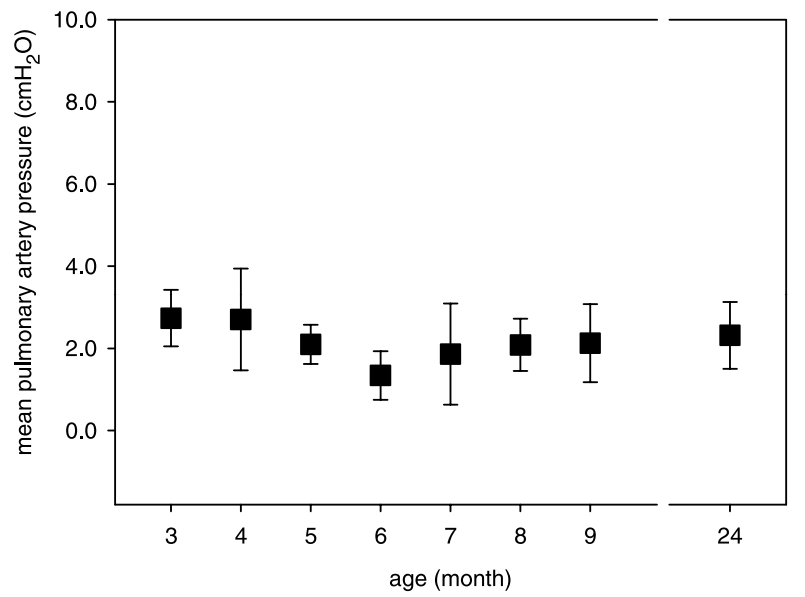

Fig. 4. Age-dependency of the mean pulmonary artery pressure in the isolated mouse lungs. Mean data \pm SD are given with $P<0.05$ as determined by ANOVA test.

of this ex vivo system, age-related changes have been particularly observed for the relative maximal expiratory flow rate and lung compliance, whereas perfusion flow and vascular permeability were not influenced by age. Changes in the biomechanical parameters indicated that maximal function of the lung is achieved in the early adulthood (5 to 6 months of age).

Developmental alveolarization (i.e. septal anlage) of the mouse lung is completed after about one month of age but growth of the lung parenchyma still continuous for more than two months [16, 20]. Due to concurrent changes in the somatic growth, the ratio of lung weight to body weight is gradually lowered with increasing age [16]. Since previous studies only analysed the development of mouse lungs in the first weeks after birth, it is difficult to assess when the ratio of lung weight to body weight reaches constant levels $[16,20]$. According to plethysmographic investigations of growing mice, the inspiratory $\mathrm{V}_{\mathrm{T}}$ is constant at the age of 3 months [10,30], but at this age the body weight has not yet reached its maximum. Our own measurements in another study indicate a constant ratio of lung weight and body weight when C57BL/6N mice are between 4 to 4.5 months old (unpublished data). Since the buffer-perfused system for mouse lung, in which the lung remains in the opened thoracic cage, does not 
allow the measurement of the lung weight, a lung weight-adapted $\mathrm{V}_{\mathrm{T}}$ could also not be used. This is a disadvantage when investigating mice of very different ages with the negative pressure-based "Isolated lung perfusion system" or with other technologies, which are based on the weight-adapted respiratory volume. Consequently, the experimental $\mathrm{V}_{\mathrm{T}}$ values we applied for lungs from young mice were probably lower in relation to their total lung capacity in vivo than in lungs from adult mice. Similar inaccuracy may have occurred for the $\mathrm{V}_{\mathrm{T}}$ values in old mice due to the weight loss with advanced age. This fact might influence some of our findings, in particular the MEF data, which depend on the respiratory volume used for ventilation of mice [31]. Despite this disadvantage, it is important to note that studies at the weight-adapted $\mathrm{V}_{\mathrm{T}}$ might still be preferred by most researchers because they ensure at least similar lung ventilations per total lung capacity.

Analysis of growing humans suggested that the MEF positively correlates with the lung volume ${ }^{b}$ where the exponent $b$ is between 0.67 and 1.0 [29]. Although our study based on the weight-adapted $\mathrm{V}_{\mathrm{T}}$, we also calculated an exponent $b>0.67$ for isolated lungs of young mice but lower values for lungs of adult and old mice. Since the relationship of MEF and weight-adapted $\mathrm{V}_{\mathrm{T}}$ is influenced by age, a general correction of the MEF per weight-adapted $\mathrm{V}_{\mathrm{T}}$ is not absolutely exact. Nevertheless, the $\mathrm{V}_{\mathrm{T}}$-corrected MEF indicated maximal expiratory lung function in the early adulthood (5 to 6 months of age). The maximum expiratory function of the isolated lung is also indicated by the highest MEF in relation to the MIF in this age. Our observations are partially in contrast to findings of whole-body plethysmographic investigations of growing mice showing either no changes or a parallel increase of MEF and MEF between 2.5-week-old and 6-month-old mice [10,30]; however, this discrepancy may result from different airflows between the isolated lung and the total respiratory system.

Like $\mathrm{V}_{\mathrm{T}}$-mediated correction of the MEF, its correction per MIF might also not be useful in all regards, especially when the airway resistance is increased $[32,33]$. However, the resistance of conducting airways was even moderately reduced at advanced age in our and other mouse studies $[1,2]$ thereby suggesting no significant obstruction of the airflow with increasing age in mice. Since animal studies investigating rat lungs identified an age-dependent increase of the airway resistance first after inhalation of methacholine, which provokes bronchoconstriction [34], it is well conceivable that the methacholine challenge can only show an adverse effect of age on the resistance of conducting airways. Nevertheless, human studies have also indicated a rather small or even no dependency of the airway resistance on age as well [35-39].

Ageing of the respiratory system causes more problems with the expiration than inspiration [40]. This is reported in many human studies [37, 39, 41-50] and in few mouse studies as well $[1,2,51]$. If the lung volume is nearly constant the expiratory flow is mainly determined by the airway resistance and elastic properties of the lung. Since our findings did not indicate an age-related airway obstruction in mice, changes in the elastic recoil pressure seem mainly to be responsible for the reduced MEF in relation to MIF [52]. In this regard, the MIF-corrected MEF values showed a steady decline after reaching their maximum in the early adulthood of mice. This coincides with many studies exhibiting reduced elastic recoil of the lung (i.e. transpulmonary pressure) in humans [37, 42, 46, 49]. Although the respiratory musculature does not play a role when studying isolated lungs, the age-dependency of the MIF-corrected MEF shown for our isolated mouse lungs coincides with many human studies exhibiting highest forced expiratory flow rates in the early adulthood and subsequent decline with increasing age $[39,41,44,45$, 47].

Changes in the lung elastic recoil are attributed to quantitative and qualitative changes in the extracellular matrix of the lung parenchyma, in particular elastin [53]. While in growing mice the high expression rate of elastin might contribute to the high elasticity, in aged mice qualitative changes of elastin significantly might impair the elastic recoil of the lung [53]. Moreover, quantitative and qualitative changes of col- 
lagen are suggested to alter the elastic property of the lung parenchyma in an age-dependent manner $[54,55]$. Age-dependent changes in the lung elasticity are also demonstrated in our ex vivo study by the higher compliance of isolated mouse lungs with increasing age. The age-dependent increase in either static or dynamic lung compliance has also been shown in other mouse studies $[1,2,51]$ as well as in human studies [39,48]. Although increased lung compliance can also be caused by greater lung volumes, for instance due to alveolar dilation [15], parallel age-related changes in the MIF-corrected MEF again indicate the pivotal role of the reduced lung elasticity in old mice. Surprisingly, lung compliance was nearly as high in 9-month-old mice as in 24-month-old mice, and also the MIF-corrected MEF was not significantly different between 9 - and 24-month-old mice. Since only a part of the mice reaches the age of 24 months, this discrepancy could result from the positive selection of old mice. Nevertheless, relatively early changes in the lung elasticity normalized per lung volume have also been shown by static and dynamic compliance measurements in active humans [48]. Also surprisingly, expiratory flow and lung compliance were not that significantly influenced by higher mouse age as expected. One critical reason for this observation might be the application of a moderate ventilation mimicking normal breathing conditions in our ex vivo study instead of stressing the lungs with high ventilation to detect the impairment in the respiratory mechanics. In contrast to changes in the biomechanical parameters, i.e., relative maximal expiratory flow and lung compliance, we did not identify an influence of age on the arterial perfusion pressure in isolated lungs. This observation coincides with other studies demonstrating either no or a very moderate influence of increasing age on the pulmonary artery pressure in humans and dogs during rest $[56,57]$.

The respiratory system becomes more susceptible to bacterial infections with increasing age due to a functional decline of the immune system [58]. Nevertheless, the old lung is not characterized by chronic inflammation as demonstrated in many histological investigations $[18,59,60]$. This has also been indirectly confirmed by our study showing an unchanged level of pro-inflammatory TNF- $\alpha$ in the BAL fluid as well as an unchanged endothelial permeability in the isolated lungs of old mice.

Our findings indicate the importance of growth and ageing on the respiratory mechanics in isolated mouse lungs. This has to be considered in experimental pulmonary research when studying lung physiological parameters in the "Isolated lung perfusion system" for mice and most likely other species. For example, investigations of age-related changes in lung would only be meaningful when comparing aged mice with mice at the age of minimum 5 months but not younger.

\section{Acknowledgments}

This project was supported by grants of Deutsche Forschungsgemeinschaft (DFG; BA 2077/4-1) and Wilhelm Roux program at the Medical Faculty Halle (Saale) (FKZ 21/43). S. Al-Robaiy was funded by DFG (BA2077/4-1). The authors thank Amrit Mann (University Medical Centre, Mainz) for editing the manuscript.

\section{Conflict of interest}

The authors have no financial, consulting or personal relationships with other persons or organizations which could have influenced the present work. 


\section{References}

[1] Huang K, et al. Variation in senescent-dependent lung changes in inbred mouse strains. J Appl Physiol 2007;102(4):1632-9.

[2] Huang K, et al. Age-dependent changes of airway and lung parenchyma in C57BL/6J mice. J Appl Physiol 2007;102(1):200-6.

[3] Bates JH, Irvin CG. Measuring lung function in mice: The phenotyping uncertainty principle. J Appl Physiol (1985) 2003;94(4):1297-306.

[4] Irvin CG, Bates JH. Measuring the lung function in the mouse: The challenge of size. Respir Res 2003;4:4.

[5] Vanoirbeek JA, et al. Noninvasive and invasive pulmonary function in mouse models of obstructive and restrictive respiratory diseases. Am J Respir Cell Mol Biol 2010;42(1):96-104.

[6] Weissmann $\mathrm{N}$, et al. Basic features of hypoxic pulmonary vasoconstriction in mice. Respir Physiol Neurobiol 2004;139(2):191-202.

[7] Al-Robaiy S, et al. The receptor for advanced glycation end-products supports lung tissue biomechanics. Am J Physiol Lung Cell Mol Physiol 2013;305(7):L491-L500.

[8] Tankersley CG, Rabold R, Mitzner W. Differential lung mechanics are genetically determined in inbred murine strains. J Appl Physiol (1985) 1999;86(6):1764-9.

[9] Schulz H, et al. Respiratory mechanics in mice: Strain and sex specific differences. Acta Physiol Scand 2002;174(4):367-75.

[10] Flandre TD, Leroy PL, Desmecht DJ. Effect of somatic growth, strain, and sex on double-chamber plethysmographic respiratory function values in healthy mice. J Appl Physiol (1985) 2003;94(3):1129-36.

[11] Pinkerton KE, et al. Morphologic changes in the lung during the lifespan of Fischer 344 rats. Am J Anat 1982;164(2):155-74.

[12] Verbeken EK, et al. The senile lung. Comparison with normal and emphysematous lungs. 1. Structural aspects. Chest 1992;101(3):793-9.

[13] Escolar JD, et al. Changes occurring with increasing age in the rat lung: Morphometrical study. Anat Rec 1994;239(3):28796.

[14] Mizuuchi T, Kida K, Fujino Y. Morphological studies of growth and aging in the lungs of Fischer 344 male rats. Exp Gerontol 1994;29(5):553-67.

[15] Miller MR. Structural and physiological age-associated changes in aging lungs. Semin Respir Crit Care Med 2010;31(5):521-7.

[16] Amy RW, et al. Postnatal growth of the mouse lung. J Anat 1977;124(Pt 1):131-51.

[17] Mauderly JL, Hahn FF. The effects of age on lung function and structure of adult animals. Adv Vet Sci Comp Med 1982;26:35-77.

[18] Kawakami M, Paul JL, Thurlbeck WM. The effect of age on lung structure in male BALB/cNNia inbred mice. Am J Anat 1984;170(1):1-21.

[19] Harding R, Pinkerton KE. Lung Anatomy (including the Aging Lung). In: Encyclopedia of Respiratory Medicine (Laurent GJ, Shapiro SD, Eds.), Academic Press, UK, 2006, pp. 606-613.

[20] Mund SI, Stampanoni M, Schittny JC. Developmental alveolarization of the mouse lung. Dev Dyn 2008;237(8):2108-16.

[21] Thurlbeck WM, Angus GE. Growth and aging of the normal human lung. Chest 1975;67(2 Suppl):3S-6S.

[22] von Bethmann AN, et al. Hyperventilation induces release of cytokines from perfused mouse lung. Am J Respir Crit Care Med 1998;157(1):263-72.

[23] Wilson MR, et al. High tidal volume upregulates intrapulmonary cytokines in an in vivo mouse model of ventilator-induced lung injury. J Appl Physiol (1985) 2003;95(4):1385-93.

[24] Sharma AK, et al. Protection from pulmonary ischemia-reperfusion injury by adenosine A2A receptor activation. Respir Res 2009;10:58.

[25] Jaecklin T, et al. Lung-derived soluble mediators are pathogenic in ventilator-induced lung injury. Am J Physiol Lung Cell Mol Physiol 2011;300(4):L648-58.

[26] Uhlig S. The isolated perfused lung. In: Methods in pulmonary research (Uhlig S, Taylor AE, Eds.), Birkhäuser, Basel, Boston, Berlin, 1998, pp. 29-53.

[27] De Troyer A, et al. Evolution of intrathoracic airway mechanics during lung growth. J Appl Physiol Respir Environ Exerc Physiol 1978;44(4):521-7.

[28] Leeder SR, et al. Maximum expiratory flow-volume curves in children: Changes with growth and individual variability. Bull Eur Physiopathol Respir 1977;13(2):249-60.

[29] Martin TR, et al. Relationship between maximal expiratory flows and lung volumes in growing humans. J Appl Physiol (1985) 1988;65(2):822-8. 
[30] Hardie WD, et al. Postnatal lung function and morphology in transgenic mice expressing transforming growth factor- $\alpha$. Am J Pathol 1997;151(4):1075-83.

[31] Lai YL, Chou H. Respiratory mechanics and maximal expiratory flow in the anesthetized mouse. J Appl Physiol (1985) 2000;88(3):939-43.

[32] Jordanoglou J, Pride NB. A comparison of maximum inspiratory and expiratory flow in health and in lung disease. Thorax 1968;23(1):38-45.

[33] Jordanoglou J, Pride NB. Factors determining maximum inspiratory flow and maximum expiratory flow of the lung. Thorax 1968;23(1):33-7.

[34] Nagase T, et al. Mechanical interdependence in relation to age: Effects of lung volume on airway resistance in rats. J Appl Physiol 1994;77(3):1172-7.

[35] Wierich W, Hartung W. Measurements of total and intrabronchial resistances in normal and diseased isolated lungs. Bronchopneumologie 1979;29(2):116-23.

[36] Berry RB, Pai UP, Fairshter RD. Effect of age on changes in flow rates and airway conductance after a deep breath. J Appl Physiol 1990;68(2):635-43.

[37] Verbeken EK, et al. The senile lung. Comparison with normal and emphysematous lungs. 2. Functional aspects. Chest 1992;101(3):800-9.

[38] Ivanov LA. Bronchial resistance and its determining factors in middle and old age. Fiziol $\mathrm{Zh}$ Im I M Sechenova 1994;80(3):56-61.

[39] Babb TG, Rodarte JR. Mechanism of reduced maximal expiratory flow with aging. J Appl Physiol 2000;89(2):505-11.

[40] Janssens JP, Pache JC, Nicod LP. Physiological changes in respiratory function associated with ageing. Eur Respir J 1999;13(1):197-205.

[41] Arkins JA, Glaser MR, Trettel RJ. The maximal expiratory flow rate of normal individuals. Dis Chest 1960;37:496-8.

[42] Turner JM, Mead J, Wohl ME. Elasticity of human lungs in relation to age. J Appl Physiol 1968;25(6):664-71.

[43] Begin R, et al. Flow and age dependence of airway closure and dynamic compliance. J Appl Physiol 1975;38(2):199-207.

[44] Knudson RJ, et al. The maximal expiratory flow-volume curve. Normal standards, variability, and effects of age. Am Rev Respir Dis 1976;113(5):587-600.

[45] Ware $\mathrm{JH}$, et al. Longitudinal and cross-sectional estimates of pulmonary function decline in never-smoking adults. Am $\mathbf{J}$ Epidemiol 1990;132(4):685-700.

[46] Lai-Fook SJ, Hyatt RE. Effects of age on elastic moduli of human lungs. J Appl Physiol 2000;89(1):163-8.

[47] Kerstjens HA, et al. Decline of $\mathrm{FEV}_{1}$ by age and smoking status: Facts, figures, and fallacies. Thorax 1997;52(9):820-7.

[48] Chaunchaiyakul R, et al. The impact of aging and habitual physical activity on static respiratory work at rest and during exercise. Am J Physiol Lung Cell Mol Physiol 2004;287(6):L1098-1106.

[49] Galetke W, et al. Reference values for dynamic and static pulmonary compliance in men. Respir Med 2007;101(8):1783-9.

[50] Freydag A, et al. Lung volume and ventilation distribution changes by positioning and application of positive airway pressure in healthy subjects. Appl Cardiopulmonary Pathophysiol 2013;17:267-74.

[51] Hirai T, et al. Age-related changes in the static and dynamic mechanical properties of mouse lungs. Respir Physiol 1995;102(2-3):195-203.

[52] Mead J, et al. Significance of the relationship between lung recoil and maximum expiratory flow. J Appl Physiol 1967;22(1):95-108.

[53] Sherratt MJ, Tissue elasticity and the ageing elastic fibre. Age (Dordr) 2009;31(4):305-25.

[54] Bellmunt MJ, et al. Age-related fluorescence in rat lung collagen. Lung 1995;173(3):177-85.

[55] Rolewska P, et al. Age-related expression, enzymatic solubility and modification with advanced glycation end-products of fibrillar collagens in mouse lung. Exp Gerontol 2013;48(1):29-37.

[56] Lam CS, et al. Age-associated increases in pulmonary artery systolic pressure in the general population. Circulation 2009;119(20):2663-70.

[57] Kovacs G, et al. Pulmonary arterial pressure during rest and exercise in healthy subjects: A systematic review. Eur Respir J 2009;34(4):888-94.

[58] Meyer KC. Aging. Proc Am Thorac Soc 2005;2(5):433-9.

[59] Teramoto S. Age-related changes in lung structure and function in the senescence-accelerated mouse (SAM): SAM-P/1 as a new model of senile hyperinflation of lung. Am J Respir Crit Care Med 1997;156(4 Pt 1):1361.

[60] Fukuchi Y. The aging lung and chronic obstructive pulmonary disease: Similarity and difference. Proc Am Thorac Soc 2009;6(7):570-2. 